\title{
Nonconducted P Wave Physiology Not Defined by ECG Finding
}

National Cancer Institute

\section{Source}

National Cancer Institute. Nonconducted P Wave Physiology Not Defined by ECG Finding. NCI Thesaurus. Code C135394.

An electrocardiographic finding of a P wave that either does not conduct to the ventricle or that does not result in ventricular activation. 